\title{
A qualidade do ensino público e a privatização via Programa Mais Educação
}

\section{Quality of public education and privatization through More Education Program}

\section{La calidad de la enseñanza pública e la privatización vía Programa Mais Educação (Más Educación)}

\author{
Elisangela Maria Pereira Schimonek ' \\ 'Universidade Estadual de Campinas - (UNICAMP) Campinas - SP - Brasil Email: \\ elisangela@educacao.rc.sp.gov.br
}

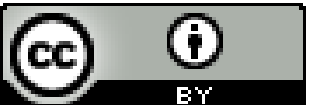

Educação: teoria e prática, Rio Claro, SP, Brasil - eISSN: 1981-8106

Está licenciada sob Licença Creative Common

\section{Resumo}

Este ensaio analisa as implicações do Programa Mais Educação (2010-2013) na garantia de uma educação de qualidade a partir do estabelecimento de parcerias público-privadas e voluntariado. O referido programa integra o Plano de Desenvolvimento da Educação e objetiva a ampliação da jornada escolar por meio da oferta de atividades complementares no contraturno escolar. A intenção proclamada é reduzir as desigualdades educacionais, promover a valorização da diversidade cultural e garantir uma educação de qualidade. Para tanto, procura-se induzir a participação de atores da sociedade civil no mapeamento de espaços para o funcionamento da educação em tempo integral, na gestão e na oferta de atividades complementares. Trata-se de um estudo qualitativo, apoiado em revisão bibliográfica e análise documental, que evidencia uma política focalizada e pautada no discurso da participação da sociedade civil como mecanismo de assunção de responsabilidades do Estado, cujos impactos para a qualidade da educação precisam ser analisados.

Palavras-chave: Educação em tempo integral. Parcerias Público-privadas. Voluntariado. Direito à educação.

\section{Abstract}

This essay examines the implications of More Education Program (2010-2013) in ensuring quality education through the establishment of public-private partnerships and volunteerism. This program integrates the Development Plan for Education and intends expanding the school day by offering additional activities after school. The proclaimed intention is to reduce educational inequalities, to promote the value of cultural diversity and to ensure education 
quality. To do so, it induces the participation of civil society actors in mapping spaces for the operation of full-time education, in the management and provision of complementary activities. This is a qualitative study, supported by literature review and documentary analysis to demonstrate a focused policy based on the discourse of civil society participation as a mechanism for taking responsibility of the State which impacts on the quality of education need to be analyzed.

Keywords: Education full time. Public-private partnerships. Volunteering. Right to education.

\section{Resumen}

Este ensayo analiza las implicaciones del Programa Mais Educação (Más Educación) (20122013) en la garantía de una educación de calidad a partir del establecimiento de colaboraciones público-privadas y voluntariado. El referido programa integra el Plan de Desarrollo de la Educación y tiene como objetivo ampliar la jornada escolar por medio de la oferta de actividades complementarias en el contraturno escolar. La intención proclamada es reducir las desigualdades educacionales, promover la valoración de la diversidad cultural y garantizar una educación de calidad. Para esto, se procura inducir la participación de actores de la sociedad civil en el mapeo de los espacios para el funcionamiento de la educación en tiempo integral, en la gestión y en la oferta de actividades complementarias. Se trata de un estudio cualitativo, apoyado en la revisión bibliográfica y el análisis documental, que evidencia una política focalizada y pautada en el discurso de la participación de la sociedad civil como mecanismo de asunción de responsabilidades del Estado, cuyos impactos para la calidad de la educación precisan analizarse.

Palabras-clave: Educación en tiempo integral. Colaboraciones Público-privadas. Voluntariado. Derecho a la educación.

\section{Introdução}

O Programa Mais Educação, instituído pela Portaria Interministerial n. 17/2007, integra o Plano de Desenvolvimento da Educação (PDE) e prevê a ampliação da jornada escolar e a organização curricular na perspectiva da educação em tempo integral, por meio da oferta de atividades complementares (oficinas pedagógicas e culturais) no contraturno escolar.

O Programa Mais Educação destina-se às escolas de baixo Ideb (índice de desenvolvimento da educação básica), situadas em regiões de vulnerabilidade social, que requeiram a convergência prioritária de políticas públicas e educacionais. Sua intenção é diminuir as desigualdades educacionais, viabilizar a valorização da diversidade cultural e garantir uma educação de qualidade (BRASIL, 2007).

O programa prevê a descentralização de recursos para sua implantação. Estes são destinados para a aplicação em materiais de consumo (custeio), permanentes (capital) e para pagamento das despesas de transporte e alimentação dos monitores/oficineiros que conduzirão as atividades complementares (BRASIL, 2013). 
Faz-se necessário questionar se a forma com que essa política vem sendo implantada, convocando a sociedade civil para assumir atribuições do Estado, de fato contribui para a melhoria da qualidade da educação pública.

Como ponto de partida, optamos por tomar o final do século $\mathrm{XX}$, apresentando as mudanças sociais e econômicas ocorridas em virtude da crise do capitalismo, as quais acarretaram alterações no modelo de ação estatal. Nesse contexto, emergiu um setor social (terceiro setor) que passou a assumir um papel suplementar à ação do Estado na oferta de serviços sociais, especialmente os voltados aos grupos mais vulneráveis, e no campo educacional houve a retirada de algumas iniciativas estatais em prol do referido setor. Em seguida, contrastamos alguns dos avanços decorrentes da Constituição Federal de 1988, sobretudo no que tange ao direito à educação, com os impasses ou retrocessos verificados no período de reforma do Estado brasileiro. Finalmente, analisamos a política do MEC (Programa Mais Educação) e seus impactos no ensino público, destacando a reconfiguração das atribuições do Estado, que passou a induzir a sociedade civil, por meio de parcerias público-privadas e voluntariado, a assumir responsabilidades inerentes a ele.

\section{Neoliberalismo e terceira via: estratégias para a superação da crise capitalista}

Com a crise do capitalismo, sobretudo a partir da década de 1970, e a consolidação das principais estratégias para a sua superação (neoliberalismo, globalização, reestruturação produtiva e terceira via), foram redefinidas as atribuições do Estado, principalmente no que tange às políticas sociais, o que teve profundo impacto na relação público-privado.

O ideário neoliberal passou a disseminar que o Estado causara a crise enfrentada pelo capitalismo, pois era ineficiente e não estabelecia mecanismos de controle fiscal. Em compensação, o mercado e o privado seriam sinônimos de qualidade, eficiência, eficácia e equidade. Nessa direção, Peroni e Adrião (2005) apresentam os pressupostos do neoliberalismo:

Para a teoria neoliberal, não é o capitalismo que está em crise, mas o Estado. Portanto, a estratégia adotada para a superação da crise seria a reforma do Estado por meio da diminuição de sua atuação. Em linhas gerais, segundo essa perspectiva, duas causas levaram à crise do Estado: a primeira deve-se a um excessivo gasto governamental gerado pela permanente necessidade de se legitimar por meio do atendimento às demandas da população por políticas sociais, o que provocou a crise fiscal [...]. A segunda causa encontrava-se no papel regulador desempenhado pelo Estado na esfera econômica, prática que atrapalhava o livre andamento do mercado. (PERONI; ADRIÃO, 2005, p. 138).

Logo, os setores que antes eram administrados e geridos pelo Estado deveriam ser transferidos para a iniciativa privada, que se mostrava uma prestadora de serviços mais eficaz. 
Reforçou-se uma política de privatização de serviços e empresas estatais, a fim de que o Estado não interferisse em seus processos.

Assim, ocorreu a flexibilização das relações entre o público e o privado, ou seja, políticas antes efetivadas pelo setor público, foram repassadas para o setor privado, com financiamento público. Nessa lógica, o Estado não gastou menos, mas houve uma nova reconfiguração das políticas, abrindo espaço para a criação de um mercado para a execução das políticas sociais, no qual o capital passou a ganhar com ele.

Peroni e Adrião (2005) destacam que foram duas as prescrições para a superação da crise: a racionalização de recursos, entendida como a diminuição da extensão das políticas sociais existentes, e o esvaziamento de poder das instituições governamentais, que, além de mais permeáveis às pressões e demandas da população, perdiam em eficiência se comparadas às de mercado. Em outras palavras, as duas estratégias neoliberais consistiam em transferir a responsabilidade pela execução e pelo financiamento das políticas sociais para o mercado, por meio da privatização da estrutura estatal, e aplicar a lógica mercantil ao que fosse mantido no âmbito do Estado.

Comungando do mesmo diagnóstico neoliberal de que o Estado era o causador da crise, por ser ineficiente e não fixar mecanismos de controle fiscal, surgiu, nos anos 1990, outra tentativa de superação da crise: a terceira via.

Apesar da semelhança com o neoliberalismo, Peroni (2012, p. 21) especifica algumas diferenças: o neoliberalismo propôs a diminuição do papel do Estado (Estado mínimo), por meio da privatização e do estabelecimento do mercado como parâmetro para a gestão pública; a terceira via propôs reformar o Estado, tendo o mercado como parâmetro de qualidade, por intermédio da administração gerencial, para fortalecer a lógica mercadológica na administração pública. Nos dois casos, a responsabilidade pela execução das políticas sociais deveria ser repassada para a sociedade: para os neoliberais, por meio da privatização (mercado), e para a terceira via, pelo terceiro setor.

Assim, observa-se que a intenção, tanto do neoliberalismo como da terceira via, era racionalizar recursos, minimizando os gastos do Estado com políticas sociais.

Quanto ao terceiro setor, Cardoso (2005, p. 81) o define como uma esfera privada (re)nova(da), que emergiu das novas formas de relacionamento do Estado com a sociedade civil e com o mercado, para atuar na intersecção dos setores público, privado empresarial e privado não empresarial.

Não demorou que o terceiro setor, concebido no espaço entre as esferas estatal e privada (denominado no Brasil de público não estatal), passasse a assumir a responsabilidade pela execução de políticas sociais.

A terceira via propôs que o governo se ajustasse às novas demandas da era global, de modo que a autoridade e a legitimidade do Estado fossem reafirmadas pela "[...] ação em parceria com instituições da sociedade civil para fomentar a renovação e o desenvolvimento da comunidade". Isso indicava que "[...] a promoção de uma sociedade civil ativa é uma parte básica da política de Terceira Via” (GIDDENS, 2001, p. 79).

A sociedade civil passou a atuar, de forma mais direta, na implantação de políticas sociais. Com a diminuição das atribuições do Estado, abriu-se espaço para o terceiro setor, Educação: Teoria e Prática/ Rio Claro/ Vol. 25, n.50/ p. 502-516/ Set.-Dez. 2015. 
que ocupa um lugar não estatal, ou seja, privado, mas voltado ao atendimento das variadas demandas públicas.

Segundo Peroni (2012, p. 24), outro ponto de divergência entre o neoliberalismo e a terceira via é a relação com a democracia. Enquanto o neoliberalismo critica a democracia, por considerar que ela atrapalha o livre andamento do mercado, a terceira via defende sua radicalização, já que, com a transferência de responsabilidades pela execução de políticas, a sociedade civil seria levada a participar.

Nesse último caso, a ideia é firmar parcerias público-privadas para a execução de políticas sociais, ou seja, o setor privado passa a intervir junto à administração pública, assumindo responsabilidades que pertenciam ao poder público. Assim, a essência das parcerias público-privadas é o encolhimento do Estado em prol da iniciativa privada. Nesse contexto, princípios como igualdade de direitos e universalização são substituídos por filantropia e ações focalizadas em grupos restritos.

\section{Direito à educação de qualidade versus privatização}

No contexto brasileiro, a década de 1980 foi marcada por relações democráticas. Grandes movimentos grevistas, o movimento Diretas Já (pelo retorno das eleições para governantes) e a luta pelas liberdades democráticas, entre outras ações, configuraram um contexto de maior participação e de democratização das várias esferas da sociedade brasileira, incluindo a organização do próprio Estado (ADRIÃO; CAMARGO, 2001, p. 69).

Em meio a essas lutas políticas, foi promulgada a Constituição Federal de 1988, com uma perspectiva mais humanizada da garantia dos direitos sociais, acenando inclusive para a possibilidade de se instituir no Brasil um Estado de bem-estar social.

Apesar de a educação em tempo integral ${ }^{1}$, objeto deste estudo, não ter sido pauta da Constituição Federal de 1988, é importante destacar que a educação integrou o primeiro dos dez direitos sociais expressos na Carta Magna: "Art. $6^{\circ}$ - São direitos sociais a educação, a saúde, a alimentação, o trabalho, a moradia, o lazer, a segurança, a previdência social, a proteção à maternidade e à infância, a assistência aos desamparados, na forma desta Constituição" (BRASIL, 1988, s/p). Logo, a educação é reconhecida como um dos direitos fundamentais para a cidadania.

Também é de grande relevância o art. 205 da Constituição Federal de 1988, que dispõe: “A educação, direito de todos e dever do Estado e da família, será promovida e incentivada com a colaboração da sociedade, visando ao pleno desenvolvimento da pessoa, seu preparo para o exercício da cidadania e sua qualificação para o trabalho" (BRASIL, 1988,

\footnotetext{
${ }^{1}$ Explicita-se apenas a garantia do direito à educação, mas não é mencionado se a jornada do aluno deve ser de tempo integral, e tampouco a legislação infraconstitucional diz que esse direito deve ser efetivado em escola de tempo integral. Logo, o assunto não está constitucionalizado. O que se observa é que, por demandas devidas à necessidade de melhoria dos resultados educacionais, à inserção da população feminina no mercado de trabalho e à vulnerabilidade social, alguns sistemas vêm ampliando suas jornadas aos poucos, e introduzindo, paulatinamente, a escola de tempo integral. Mas, para se tornar um direito do aluno e um dever do Estado, a educação em tempo integral ainda deve ser pauta de lutas e disputas.

Educação: Teoria e Prática/ Rio Claro/ Vol. 25, n.50/ p. 502-516/ Set.-Dez. 2015.
} 
s/p). Com isso, determina-se o dever do Estado para com a educação e fica composta a tríade Estado, família e sociedade, responsável por promover e incentivar a educação.

A Emenda Constitucional (EC) $n^{\circ}$ 59/2009 modificou o inciso ${ }^{2}$ do art. 208 da Carta Magna, dando-lhe a seguinte redação:

Art. 208. O dever do Estado com a educação será efetivado mediante a garantia de:

I - educação básica obrigatória e gratuita dos 4 (quatro) aos 17 (dezessete) anos de idade, assegurada inclusive sua oferta gratuita para todos os que a ela não tiveram acesso na idade própria [...] (BRASIL, 1988, s/p).

Apesar da relevância dessa EC, por ampliar a obrigatoriedade do ensino, o limite etário acabou por excluir a população de 18 anos ou mais. Trata-se de uma imprecisão que merece ajuste.

Destacamos, ainda, o disposto no art. 206: “O ensino será ministrado com base nos seguintes princípios: I. igualdade de condições para o acesso e permanência na escola [...] VII. garantia de padrão de qualidade [...]" (BRASIL, 1988, s/p). Assim, para além das questões de acesso e permanência dos alunos na escola, é preciso repensar tal padrão de qualidade ${ }^{3}$, com vistas a assegurar aos sujeitos um efetivo processo de aprendizagem e desenvolvimento integral.

Oliveira e Araújo (2005) afirmam que, no Brasil, a noção de qualidade já teve três significados distintos: o primeiro era condicionado pela oferta limitada de oportunidades de escolarização; o segundo relacionava-se à ideia de fluxo, definido como o número de alunos que progridem ou não dentro de determinado sistema de ensino; o terceiro associa-se à aferição de desempenho mediante testes em larga escala.

Atualmente, no Brasil, o acesso e a permanência dos alunos no ensino obrigatório estão quase universalizados, e a consolidação de um indicador (Ideb) ${ }^{4}$, que se proclama um mecanismo para medir a qualidade, também é realidade. Porém, ainda se observa que muitos alunos não avançam no processo de aprendizagem:

Diante da quase universalização do acesso à etapa obrigatória de escolarização, bem como dos reiterados episódios trazidos pela imprensa e vividos no cotidiano escolar quanto aos alunos que estão na escola, mas não

\footnotetext{
${ }^{2}$ A primeira redação do referido inciso definia, como dever do Estado, a garantia de "ensino fundamental, obrigatório e gratuito, inclusive para os que a ele não tiveram acesso na idade própria". Apesar de o inciso contemplar apenas o ensino fundamental como obrigatório, o preceito não limitou a faixa etária, o que constituía um avanço. Para Oliveira (1995, p. 9), no que diz respeito à declaração do direito à educação, a Carta Constitucional de 1988 representou um salto de qualidade em relação à legislação anterior, deslocando o debate sobre a efetivação desse direito da esfera jurídica para a esfera da luta social. Isso porque, com a maior precisão da redação e o detalhamento da declaração, suprimiram-se os obstáculos legais à universalização do ensino fundamental (para todos e em todas as idades) e explicitaram-se até mesmo os instrumentos jurídicos para a sua efetivação.

${ }^{3}$ A educação em tempo integral tem sido considerada, por muitos governos, uma estratégia para assegurar a melhoria do ensino.

${ }^{4}$ É importante ressaltar que o Ideb é apresentado nas políticas oficiais como o PNE 2014-2024, com essa intenção - aferir a qualidade do ensino. No entanto, sua ênfase recai sobre os resultados em detrimento dos processos de aprendizagem e, ainda, se induz à responsabilização/culpabilização unilateral da escola, a partir da publicização dos índices educacionais, gerando comparação entre escolas.

Educação: Teoria e Prática/ Rio Claro/ Vol. 25, n.50/ p. 502-516/ Set.-Dez. 2015.
} 
se apropriam do mínimo indispensável para viver em sociedade, parece que o grande desafio do atual momento histórico, no que diz respeito ao direito à educação, é fazer com que ele seja, além de garantido e efetivado por meio de medidas de universalização do acesso e da permanência, uma experiência enriquecedora do ponto de vista humano, político e social, e que consubstancie, de fato, um projeto de emancipação e inserção social. Portanto, que o direito à educação tenha como pressuposto um ensino básico de qualidade para todos e que não (re)produza mecanismos de diferenciação e de exclusão social (OLIVEIRA; ARAÚJO, 2005, p. 16).

Considerando a educação como um direito público e subjetivo, e que o Estado tem o dever de promovê-la com qualidade, é fundamental definir o que se entende por padrão de qualidade ${ }^{5}$, para viabilizar sua exigência na forma da lei.

Oliveira (2011) discorre sobre a necessidade de uma conceituação de qualidade que permita transformar o princípio constitucional em realidade. Dada a dificuldade de caracterizar e aferir a qualidade, o autor sugere a criação de um indicador que articule três dimensões: insumos, resultados e processos. Além disso, enfatiza a importância de avançarmos nessa discussão, para desenvolver um indicador de monitoramento do sistema no que tange à garantia de uma educação de qualidade, de modo que esse direito possa ser exigido junto à Justiça.

O estabelecimento de um indicador de qualidade, que abarque as referidas dimensões, é condição sine qua non para o acompanhamento do sistema educacional e a formulação de políticas capazes de assegurar um ensino público de qualidade.

Apesar das conquistas consolidadas no texto constitucional, a década de 1990 foi um período de mudanças nas atribuições do Estado, com profundo impacto nas políticas sociais, conforme explicam Oliveira e Araújo (2005):

Todavia, logo após a promulgação da constituição, implementam-se no Brasil políticas ancoradas na visão da necessidade do redimensionamento do papel do Estado nas políticas sociais e do ajuste fiscal. Isso criou um fosso entre as conquistas e garantias estabelecidas e as necessidades relativas ao controle e diminuição dos gastos públicos (OLIVEIRA; ARAÚJO, 2005, p. $6)$.

O governo Fernando Henrique Cardoso (FHC - 1995-2002) acenou que a crise brasileira das últimas décadas fora, também, uma crise do Estado, pois este se desviara de funções básicas para ampliar sua presença no setor produtivo, fato que culminou em uma gradual deterioração dos serviços públicos e no agravamento da crise fiscal e da inflação. A reforma do Estado foi proposta objetivando uma maior estabilização social e o crescimento sustentável da economia. Tratava-se da redefinição das atribuições do Estado, que deixou de “[...] ser o responsável direto pelo desenvolvimento econômico e social pela via da produção de bens e serviços, para fortalecer-se na função de promotor e regulador desse desenvolvimento" (BRASIL, 1995, s/p).

\footnotetext{
${ }^{5}$ De acordo com Duarte (2007, p. 706), existem alguns parâmetros objetivos que servem como orientação nessa matéria, tais como o grau de formação dos professores, a disponibilidade de material didático e de apoio, a adequação dos currículos à realidade local, a implantação de sistemas de avaliação e a melhoria da remuneração e das condições de trabalho dos professores, entre outros.

Educação: Teoria e Prática/ Rio Claro/ Vol. 25, n.50/ p. 502-516/ Set.-Dez. 2015.
} 
Para atender às crescentes demandas da sociedade, considerou-se necessária uma reorganização do Estado que levasse em conta critérios de gestão capazes de reduzir custos, uma maior articulação com a sociedade, a definição de prioridades e a cobrança de resultados.

FHC instituiu o Ministério da Administração Federal e Reforma do Estado (MARE), nomeando o economista Luiz Carlos Bresser Pereira para conduzi-lo, e, ao propor a Reforma do Aparelho do Estado, pautou-se em uma perspectiva de administração gerencial.

Segundo Bueno e Kassar (2005, p. 120), Bresser Pereira elaborou o Plano Diretor da Reforma do Aparelho do Estado (PDRAE) pretendendo atingir, basicamente, quatro aspectos da administração pública: o tamanho do Estado; o papel regulador do Estado; a governança, ou seja, "a capacidade de tornar efetivas as decisões do governo", e a governabilidade, isto é, o poder do governo.

O Estado assumiu o papel de formulador, regulador e avaliador das políticas públicas, reduzindo seu papel de executor e prestador de serviços.

Bresser Pereira (1998, p. 33) propôs a organização do Estado em quatro setores: o núcleo estratégico, as atividades exclusivas, os serviços não exclusivos e a produção de serviços para o mercado. A educação foi incluída entre os serviços não exclusivos do Estado, o que favoreceu a abertura de espaço ao setor privado e ao setor público não estatal:

Serviços não-exclusivos são todos aqueles que o Estado provê, mas que, como não envolvem o exercício do poder extroverso, podem ser também oferecidos pelo setor público não estatal ("não governamental"). Esse setor compreende os serviços de educação, saúde, culturais e de pesquisa (PEREIRA, 1998, p. 34).

Introduziu-se a ideia de transferir para o setor privado as atividades que pudessem ser controladas pelo mercado por via da privatização, terceirização e publicização (forma de transformar as instituições públicas estatais em organizações sociais de direito privado, reforçando a concepção de público não estatal). Com o processo de publicização, os serviços que, anteriormente, tinham caráter público e eram oferecidos pelo Estado, passaram a ser ofertados pelo terceiro setor (público não estatal), constituído por agentes privados e organizações da sociedade civil (SCHIMONEK, 2012).

Adrião e Peroni (2005, p. 9) afirmam que, com o alargamento da esfera pública não estatal, ocorreu a supressão de iniciativas estatais para a oferta e/ou manutenção de diferentes etapas de escolarização. As demandas educacionais, em especial as não contempladas pelas etapas da obrigatoriedade ${ }^{6}$, passaram a ser atendidas privadamente, por atores sociais atomizados: instituições educacionais privadas, ONGs, empresas, grupos comunitários locais ou de interesse específico, igrejas etc., que usufruíam de subvenção pública.

Essa política de racionalização de gastos e transferência da responsabilidade pelos serviços não exclusivos (entre eles a educação) ao setor público não estatal afetou, negativamente, a qualidade do ensino. Políticas focais para grupos restritos passaram a ser concebidas, com pouco investimento e impacto no ensino público.

\footnotetext{
${ }^{6}$ Como a educação em tempo integral, cuja oferta vem sendo objeto de parcerias público-privadas e voluntariado.

Educação: Teoria e Prática/ Rio Claro/ Vol. 25, n.50/ p. 502-516/ Set.-Dez. 2015.
} 
Para a educação, esse contexto representou o acirramento das tensões entre as expectativas de melhoria da qualidade dos sistemas de ensino e a disponibilidade de recursos orçamentários para a consecução desse fim. Isso favoreceu uma perspectiva de qualidade cuja lógica tinha por base as ideias de eficiência e produtividade, com uma clara matriz empresarial, em contraposição à ideia de democratização da educação e do conhecimento como estratégia de construção e consolidação de uma esfera pública democrática (OLIVEIRA; ARAÚJO, 2005, p. 6).

Diante do exposto, constatamos que tanto os princípios neoliberais e de terceira via, quanto aqueles que permearam a reforma do Estado brasileiro fizeram com que o Estado priorizasse a função reguladora, concebesse políticas educacionais focalizadas e fragmentadas, transferisse responsabilidades para a sociedade civil e abrisse espaço para os setores privado e público não estatal. Em nome da participação, a sociedade civil passou a ser convocada para assumir tarefas inerentes ao Estado, ampliando o mercado educacional e reforçando a tese da desresponsabilização do poder público com relação às políticas educacionais.

De acordo com Peroni (2012, p. 23), tanto o processo de publicização - com a passagem para o público não estatal, principalmente por meio de parcerias público-privadas quanto a proposta de gestão gerencial tiveram continuidade nos governos Lula (2003-2010) e Dilma Roussef (2011-2014). Exemplo disso é o Programa Mais Educação, abordado a seguir.

Apesar disso, é importante destacar que ocorreram importantes ações desses governos na área social, em especial na educação: houve a ampliação do direito à educação dos 4 aos $17 \operatorname{anos}^{7}$ (da creche ao ensino médio, incluindo modalidades de ensino), o fortalecimento do ensino superior pela via pública e campi federais, ampliação do financiamento à educação, entre outros, que são exemplos de rupturas com relação ao governo anterior.

\section{Programa Mais Educação: qualidade do ensino via privatização}

A Lei de Diretrizes e Bases da Educação Nacional (LDB, Lei 9394/96), em seu art. $4^{\circ}$, inciso IX, prescreve que o dever do Estado de efetivar o direito à educação será concretizado mediante a garantia de “[...] 'padrões mínimos de qualidade de ensino', definidos como a variedade e a quantidade mínimas, por aluno, de insumos indispensáveis ao desenvolvimento do processo de ensino-aprendizagem” (BRASIL, 1996 apud ARAÚJO; OLIVEIRA, 2005, p.17). Assim, em consonância com a CF/1988, além da garantia de acesso, permanência, sucesso e aprendizagem do aluno no ensino obrigatório, o Estado deve assegurar que a sua oferta educacional seja de qualidade.

\footnotetext{
${ }^{7}$ EC no 59 de 11/11/2009.

Educação: Teoria e Prática/ Rio Claro/ Vol. 25, n.50/ p. 502-516/ Set.-Dez. 2015.
} 
Considerando a necessidade de melhorar os resultados educacionais, e entendendo que essa conquista equivale a uma educação de qualidade, alguns governos, nas últimas décadas, têm concebido programas/projetos de educação em tempo integral como estratégia para viabilizar melhores índices educacionais, a proteção e a promoção social dos alunos oriundos de áreas de vulnerabilidade social.

Com relação à ampliação da jornada escolar, a LDB determina:

Art. 34. A jornada escolar no ensino fundamental incluirá pelo menos quatro horas de trabalho efetivo em sala de aula, sendo progressivamente ampliado o período de permanência na escola.

[...] $\S 2^{\circ} \mathrm{O}$ ensino fundamental será ministrado progressivamente em tempo integral, a critério dos sistemas de ensino. [...]

Art. 87. [...] $§ 5^{\circ}$ Serão conjugados todos os esforços objetivando a progressão das redes escolares públicas urbanas de ensino fundamental para o regime de escolas de tempo integral (BRASIL, 1996, p. 27840).

Esses artigos fixam o compromisso de ampliar, gradativamente, o tempo do aluno na escola, mas o restringem ao ensino fundamental. Ainda, ao prescrever a união de esforços para a oferta de educação integral, a LDB reforça a importância do regime de colaboração entre os entes federados.

O Programa Mais Educação, instituído pela Portaria Interministerial n ${ }^{\text {o }}$ 17/2007, integra o PDE e prevê a ampliação da jornada escolar, destinando-se, prioritariamente, às escolas de baixo Ideb, localizadas em regiões de vulnerabilidade social. Apresenta-se como uma estratégia para reduzir as desigualdades educacionais, viabilizar a valorização da diversidade cultural e garantir uma educação de qualidade. Cabe-nos indagar se o programa, de fato, tem impacto positivo na melhoria da qualidade do ensino público.

O Decreto n⿳⺈ 7083/2010, que dispõe sobre o Programa Mais Educação, descreve no art. $3^{\circ}$ os seus objetivos:

I - formular política nacional de educação básica em tempo integral;

II - promover diálogo entre os conteúdos escolares e os saberes locais; [...]

V - convergir políticas e programas de saúde, cultura, esporte, direitos humanos, educação ambiental, divulgação científica, enfrentamento da violência contra crianças e adolescentes, integração entre escola e comunidade, para o desenvolvimento do projeto político-pedagógico de educação integral (BRASIL, 2010, p. 2).

Nota-se que a proposta do referido programa reconhece a importância de valorizar os saberes oriundos da sociedade, relacionando-os aos conhecimentos formais sistematizados e ministrados nas escolas, além de defender a convergência de políticas públicas para a implantação da educação em tempo integral. 
A Portaria Interministerial $\mathrm{n}^{\circ}$ 17/2007 determina, em seu art. $6^{\circ}$, as diretrizes e orientações para a implantação do programa, criando a possibilidade de instituições privadas e outras organizações ou parcerias da sociedade civil ofertarem atividades complementares gratuitas:

O Programa Mais Educação visa fomentar, por meio de sensibilização, incentivo e apoio, projetos ou ações de articulação de políticas sociais e implementação de ações socioeducativas oferecidas gratuitamente a crianças, adolescentes e jovens e que considerem as seguintes orientações: [...] VI. fomentar a participação das famílias e comunidades nas atividades desenvolvidas, bem como da sociedade civil, de ONG's e esfera privada (BRASIL, 2007, p. 5).

Com isso, em vez de apresentar uma atuação efetiva na oferta de educação em tempo integral e de qualidade, o Estado vai se retirando ao direcionar novas atribuições à sociedade civil e às escolas.

No que se refere ao espaço físico a ser utilizado para a implantação do programa, encontramos outra prescrição, voltada à desresponsabilização do Estado quanto à educação pública, no art. $8^{\circ}$ da portaria supracitada: “[...] mobilizar e estimular a comunidade local para oferta de espaços buscando sua participação complementar em atividades e outras formas de apoio que contribuam para o alcance das finalidades do Programa" (BRASIL, 2007, p.5). O documento Programa Mais Educação: gestão intersetorial no território também trata do assunto: “[...] o espaço físico da escola não é determinante para a oferta da educação integral" e "[...] o mapeamento de espaços, tempos e oportunidades é tarefa que deve ser feita com as famílias, os vizinhos, enfim, toda a comunidade" (BRASIL, 2009, p. 16).

Assim, a falta de espaço físico não é considerada um impedimento para a efetivação dessa política, pois sua viabilização ocorre por meio do incentivo ao voluntariado, do estabelecimento de parcerias público-privadas e da gestão participativa da comunidade local.

A política de educação de tempo integral em discussão propõe a realização de atividades complementares no contraturno escolar, sem prever a articulação delas com o projeto político-pedagógico das escolas. Desse modo, os resultados podem ficar comprometidos em termos qualitativos, conforme afirma Silva:

Consideramos que a organização curricular indicada pelo Programa poderá não ser concretizada na realidade escolar de forma planejada e organizada, até porque muitas escolas, por conta da necessidade de dar início ao Programa apressadamente, podem ter aderido à oferta de atividades extras sem, no entanto, incorporá-las à sua proposta pedagógica. Essa não concretização se configura como uma negação de direitos, uma vez que o Programa deveria promover e garantir, sob a perspectiva do direito da educação para todos, a permanência e a aprendizagem de seus participantes. Nesse sentido, pensar em uma educação de qualidade pressupõe [...] explicitar as dimensões, os fatores e indicadores de qualidade que expressem a complexidade do fenômeno educativo (SILVA, 2012, p. 95).

O MEC prevê a descentralização de recursos para as escolas (via PDDE) a fim de possibilitar a implantação da educação em tempo integral, observada uma jornada mínima de sete horas diárias. Os recursos são destinados à aplicação em custeio (envolvendo o Educação: Teoria e Prática/ Rio Claro/ Vol. 25, n.50/ p. 502-516/ Set.-Dez. 2015. 
pagamento de despesas com oficineiros) e capital. Cada escola recebe duas parcelas de recursos financeiros, cada uma correspondente a dez meses letivos, como apoio à implantação do programa. Após esse período (vinte meses letivos), assiste-se à retirada do MEC no que se refere à garantia do repasse, e toda a responsabilidade pela educação em tempo integral é transferida aos municípios e escolas ${ }^{8}$.

O programa propõe a contratação de oficineiros (voluntários) para a condução das atividades complementares realizadas no contraturno escolar. Para o ressarcimento das despesas (transporte e alimentação) desses voluntários, há um repasse mensal de, no máximo, $\mathrm{R} \$ 400,00$, considerando-se o número de turmas monitoradas. Trata-se de uma política de baixo custo, que prevê o atendimento com base na racionalização de gastos.

Isso evidencia a concepção mercadológica do programa: atender mais com menos, atrelando a utilização racional dos recursos a resultados e metas (melhoria do Ideb e alívio da pobreza $a^{9}$ ), e dando à educação em tempo integral um caráter de serviço para os mais pobres.

O programa proclama-se como uma política capaz de diminuir as desigualdades educacionais, garantir uma educação de qualidade e, portanto, possibilitar a obtenção de melhores resultados educacionais (Ideb). No entanto, em vez de promover a contratação de docentes qualificados, implanta ações paliativas, assistencialistas e compensatórias por meio do voluntariado e de parcerias público-privadas. Com isso, a tendência é que as desigualdades sejam acirradas, e não minimizadas, agravando a dualidade perversa da escola pública: "[...] uma escola do conhecimento para os ricos e escola do acolhimento social para os pobres" (LIBÂNEO, 2012, p. 13).

Ao estimular a articulação com a sociedade civil para viabilizar espaços, a gestão e a condução das atividades complementares, o MEC induz a ampliação da jornada escolar e, ao mesmo tempo, minimiza a responsabilidade do poder público pela oferta de educação integral de qualidade. Tal tendência alinha-se aos princípios que nortearam a reforma do Estado brasileiro e a pressupostos neoliberais e da terceira via. Logo, fica evidente que ainda estamos longe da igualdade de oportunidades educacionais, e que aos diferentes grupos sociais são oferecidos sistemas escolares diferentes e desiguais (DUBET, 2004, p. 545).

\section{Considerações finais}

Guiada por diretrizes mercadológicas e gerenciais, a atual política do MEC de ampliação da jornada escolar (Programa Mais Educação) visa à racionalização dos gastos, à transferência de responsabilidades e à obtenção de melhores resultados. A atuação e a responsabilidade do Estado, no que tange à oferta de uma educação de qualidade, são minimizadas pelo incentivo à participação da sociedade civil por meio do trabalho voluntário e de parcerias público-privadas.

\footnotetext{
${ }^{8}$ As oficinas do programa podem ser trocadas anualmente, além disso, para manter o funcionamento regular do Programa, as escolas necessitam, principalmente, de material de consumo para utilizar nas diversas oficinas. Sem o repasse de recursos financeiros fica difícil a manutenção das atividades.

${ }^{9}$ Orientação do Banco Mundial.

Educação: Teoria e Prática/ Rio Claro/ Vol. 25, n.50/ p. 502-516/ Set.-Dez. 2015.
} 
O Programa Mais Educação não constitui uma proposta de educação integral de qualidade para todos; é uma política focalizada que se apoia numa perspectiva humanitária para justificar uma educação acolhedora para pobres.

Nos limites desse trabalho, não é possível afirmarmos os impactos do Programa na diminuição das desigualdades educacionais e sua contribuição para a melhoria da educação pública. No entanto, ao não prever espaço físico adequado, recursos financeiros suficientes e a articulação das atividades complementares com o projeto pedagógico das escolas, e, ainda, ao delegar a educação em tempo integral ao voluntariado e a parcerias público-privadas, temos a hipótese de que as consequências do programa quanto aos referidos aspectos serão mínimas, o que demandará uma investigação mais aprofundada da política de educação em tempo integral.

\section{Referências}

ADRIÃO, T.; CAMARGO, R. B. de. A gestão democrática na Constituição de 1988. In: OLIVEIRA, T.; ADRIÃO, T. (Orgs.). Gestão, financiamento e direito à educação. São Paulo: Xamã, 2001. p. 69-78.

ADRIÃO, T.; PERONI, V. (Orgs.). Apresentação. In: ADRIÃO, T.; PERONI, V. (Orgs.). O público e o privado na educação: interfaces entre Estado e sociedade. São Paulo: Xamã, 2005. p. 9-11.

BRASIL. Congresso Nacional. Constituição da República Federativa do Brasil. Brasília: Senado Federal, Centro Gráfico, 1988.

BRASIL. Ministério da Administração e Reforma do Estado. Plano Diretor da Reforma do Aparelho do Estado. Brasília: Câmara da Reforma do Estado, 1995.

BRASIL. Lei no 9.394, de 20/12/1996. Lei de Diretrizes e Bases da Educação Nacional. Diário Oficial da República Federativa do Brasil, Brasília, DF, 23 dez. 1996, Seção I, p. 27833-27841.

BRASIL. Portaria Normativa $\mathrm{n}^{\mathrm{o}}$ 17, de 24 de abril de 2007. Institui o Programa Mais Educação. Diário Oficial da União, Brasília, DF, 27 abr. 2007, Seção 1, p. 5-6.

BRASIL. Programa Mais Educação: gestão intersetorial no território. Brasília: MEC, 2009.

BRASIL. Decreto $\mathrm{n}^{\mathrm{o}}$ 7.083, de 27 de janeiro de 2010. Dispõe sobre o Programa Mais Educação. Diário Oficial da União, Brasília, DF, 27 jan. 2010, Seção 1, p. 2.

BRASIL. Manual operacional de educação integral. Brasília: MEC/SEB, 2013. 
BUENO, C. C. de O.; KASSAR, M. de C. M. Público e privado: a educação especial na dança das responsabilidades. In: ADRIÃO, T.; PERONI, V. (Orgs.). O público e o privado na educação: interfaces entre Estado e sociedade. São Paulo: Xamã, 2005. p. 119-135.

CARDOSO, C. M. O público no privado e o privado no público em Portugal e na Inglaterra. In: ADRIÃO, T.; PERONI, V. (Orgs.). O público e o privado na educação: interfaces entre Estado e a sociedade. São Paulo: Xamã, 2005. p. 81-117.

DUARTE, C. S. A educação como um direito fundamental de natureza social. Educ. Soc., Campinas, v. 28, n. 100, p. 691-713, Out. 2007. Disponível em: <http://www.scielo.br/pdf/es/v28n100/a0428100>. Acesso em: 19 mai. 2014.

DUBET, F. O que é uma escola justa? Cadernos de Pesquisa, São Paulo, v. 34, n. 123, p. 539-555, Set./Dez. 2004. Disponível em:

http://www.scielo.br/pdf/cp/v34n123/a02v34123.pdf>. Acesso em: 20 jul. 2014.

GIDDENS, A. A terceira via: reflexões sobre o impasse político atual e o futuro da socialdemocracia. Rio de Janeiro: Record, 2001.

LIBÂNEO, J. C. O dualismo perverso na escola pública brasileira: escola do conhecimento para os ricos e escola do acolhimento social para os pobres. Educação e Pesquisa, São Paulo, v. 38, n. 1, p. 13-28, 2012. Disponível em: 〈http://www.scielo.br/pdf/ep/v38n1/aop323.pdf>. Acesso em: 10 jun. 2014.

OLIVEIRA, R. P. de. Educação e cidadania: o direito à educação na Constituição de 1988 da República Federativa do Brasil. 1995. 187f. Tese (Doutorado em Educação) - Faculdade de Educação, Universidade de São Paulo, São Paulo, 1995.

OLIVEIRA, R. P. de. A qualidade do ensino como parte do direito à Educação: um debate em torno dos indicadores. In: FERNANDES, D. (Org.). Avaliação em educação: olhares sobre uma prática social incontornável. Pinhais: Melo, 2011. p. 117-134.

OLIVEIRA, R. P. de; ARAÚJO, G. C. Qualidade do ensino: uma nova dimensão da luta pelo direito à educação. Revista Brasileira de Educação, Rio de Janeiro, v. 28, p. 5-23, Jan./Abr. 2005.

Disponível em: <http://www.acaoeducativa.org.br/portal/images/stories/pdfs/est1_37.pdf>. Acesso em: 15 mai. 2014. 
PEREIRA, L. C. B. Gestão do setor público: estratégia e estrutura para um novo Estado. In: PEREIRA, L. C. B.; SPINK, P. K. Reforma do Estado e administração pública gerencial. Rio de Janeiro: Editora FGV, 1998. p. 21-38.

PERONI, V. M. V. A gestão democrática da educação em tempos de parceria entre o público e o privado. Pro-Posições, Campinas, v. 23, n. 2 (68), p. 19-31, Mai./Ago. 2012. Disponível em: 〈http://www.scielo.br/pdf/pp/v23n2/a03v23n2.pdf>. Acesso em: 20 jun. 2013.

PERONI, V. ; ADRIÃO, T. Público não estatal: estratégias para o setor educacional brasileiro. In: ADRIÃO, T.; PERONI, V. (Orgs.). O público e o privado na educação: interfaces entre Estado e sociedade. São Paulo: Xamã, 2005. p. 137-153.

SCHIMONEK, E. M. P. O PDE Escola: instrumento de autonomia para as unidades escolares?. 2012. 278f. Dissertação (Mestrado em Educação) - Instituto de Biociências, Unesp Rio Claro, Rio Claro, 2012.

SILVA, A. L. F. da. Ampliação da jornada escolar e a melhoria da qualidade da educação básica. ORG \& DEMO, Marília, v. 13, n. 1, p. 97-100, Jan./Jun. 2012.

Recebido em: 14/08/2014

Revisado em: 26/12/2014

Aprovado para publicação em: 29/01/2015

Publicado em: 22/12/2015 